\title{
Medical Applications of 3D Printing
}

\author{
Mojtaba Ahmadieh Khanesar* \\ Department of Mechanical, Materials and Manufacturing Engineering, Faculty of Engineering, University of Nottingham, UK
}

*Corresponding author: Mojtaba Ahmadieh Khanesar, Department of Mechanical,

Materials and Manufacturing Engineering, Faculty of Engineering, University of

Nottingham, UK.

Received Date: July 02, 2019

Published Date: July 08, 2019

\section{Abstract}

This paper presents a brief review on medical applications of one of the fast-growing technologies namely 3D printing. It provides means for fabricating 3D human organs which can be used for training purposes and planning surgeries. Moreover, 3D printed organs and prostheses can be implanted in patient body. This technology is being improved and the costs associated with that is reduced making it a vital field in biomedical engineering.

\section{Introduction}

Three-dimensional printing is a subset of additive manufacturing which refers to as layer by layer construction of a 3D object from its CAD model designed in a computer. It is a hot topic of research emerging newer topics in material and manufacturing and has already found its applications in biomedical applications and aerospace industry. Nowadays, 3D printed teeth are implanted in patient's mouth and the CAD model of spare and prototyping is done faster than ever before. Materials used in three-dimensional printing are plastic, metal, dental material and so on. Multi material 3D printing makes it possible to print a fully functional printed circuit board at one fell swoop.

Other than 3D printing of tooth which is already commercialized. Three-dimensional printing pills and cardiovascular 3D printing can be named as some of the key applications of this technology.

\section{Three-Dimensional Printing Technology}

Three-dimensional printing applications cover a wide range including aerospace, defense industry, automotive and medical purposes. Each of these applications require special materials and use application specific methods for print. Cell printing is specifically designed for medical purposes.

\section{Micro-extrusion printing}

In this method, pneumatic pressure is applied to the biomaterials and cells to dispense them on the desired 3D position. This method is most commonly used cell printing method [1].

\section{Inkjet printing}

Cell-suspended liquid in this method is injected from nozzle to appropriate position. Electrically heated nozzle or piezoelectric actuator vaporizes water. While this method is amongst cheapest methods, exposition of cells to nozzle heat is its weakness [1].

\section{Laser-assisted printing}

In this method, biological structures are patterned or prepared by laser-induced forward transfer [1].

\section{Biomedical Applications}

Three-dimensional printing is an emerging technology which is widely applied to various fields of biomedical applications. In this section, several applications are briefly discussed

\section{Application in 3D printing medical drugs}

Millions of people all around the world are in high daily demand for taking medication during day to control disease like diabetes and blood pressure. However, drugs are still manufactured in a traditional way and similar for everybody. Three-dimensional printing gives freedom of manufacturing to make drugs with custom shape, form and size to make user specific products [2]. Problems such as difficulty in swallowing large capsules may be addressed using such methods. Use of transdermal drug may also be another option by which it is also possible to lower the delivery rate of drugs [3]. 


\section{Implant and tissue design}

Due to high precision of CAD/CAM, these methods are used to make dental products with high accuracy and durability [4]. Natural and Fashionable coloring of 3D printed tooth are possible using these methods as well. Traditional methods of fabricating an auricular prosthesis is a complicated task which include several manual procedures. Soft tissue fabrication is possible using special materials. An interesting clinical report summarizes making an ear for a 30-years old patient who has lost his right ear. Computerized tomography has been used to scan his opposing ear based on which a 3D CAD model for his lost ear has been designed and 3D printed [5]. A realistic silicone prosthesis has been fabricated from three-dimensional dataset of facial surface of a patient who was in need for such prosthesis [6]. Breast reconstruction from laser scanned 3D data to obtain precise size and shape has also been investigated [7]. World first successful 3D printed kidney has been transplanted inside the body of 22-year-old female patient [8]. 3D printed mandible has been reported as another anatomical structure used in facial surgery [9,10]. Mitral Valve [11], Hip [12], femoral [13], hemi-knee joint reconstruction [13] are other surgical areas potentially benefiting from the 3D printing after appropriate processing stages.

\section{Medical research}

Highly complicated unknown physiological processes may be more easily understandable in 3D handheld model rather than 2D or 3D digital visualization of the studied organ [14]. Elastic properties of vessels can be mimicked using materials such as silicon or polyurethane $[15,16]$. 3D printed model of cancer tumor makes research on response to treatments easier [17].

\section{Medical education and training}

Visual inspection and direct manipulation of hand-held model of human organs is made possible using 3D printing. Such model makes tactile feedback and tangible depth possible [18].

\section{Simulating surgical and interventional procedures}

Performing surgery on internal human organ including heart and brain is a difficult task which requires talented and experienced surgeon. Because of special function of heart in human body and short length of anesthesia during such surgeries, surgeon may need to make instantaneous decisions. In severe and difficult surgeries, it is highly appreciable if realistic, yet safe surgery conditions are provided beforehand to avoid unpredictable situations. Vodiskat et al. used a 3D printing model of the congenital heart defect used for preoperative planning. They could successfully use an excellent CT scan and a cost-effective 3D printer to preoperatively plan a heart surgery [17]. Such process may shorten the surgery time and lessen the side effects related to anesthesia and may improve the results. The feasibility of a surgery can also be predicted in a more accurate way.

\section{Conclusion}

Three-dimensional printinghuman organs is a multidisciplinary science which falls in the intersection of biomedical engineering, material and advanced machine learning techniques. It is a trendy technology which finds its applications in various fields of biomedical engineering.

\section{Acknowledgement}

None.

\section{Conflicts of Interest}

No Conflicts of Interest

\section{References}

1. Yi HG, Lee H, Cho DW (2017) 3D Printing of Organs-On-Chips. Bioengineering 4(4): 10.

2. Beck RCR, Chaves PS, Goyanes A, Vukosavljevic B, Buanz A, et al. (2017) 3D printed tablets loaded with polymeric nanocapsules: An innovative approach to produce customized drug delivery systems. Int J Pharm 528(1-2): 268-279.

3. Economidou SN, Lamprou DA, Douroumis D (2018) 3D printing applications for transdermal drug delivery. Int J Pharm 544(2): 415-424.

4. Zhang S, Miyanaji H, Yang L, Ali Zandinejad A, Dilip J, et al. (2014) An experimental study of ceramic dental porcelain materials using a 3D print (3DP) process. Proc 25th Annu Int Solid Free Fabr Symp 991-1011.

5. Liacouras P, Garnes J, Roman N, Petrich A, Grant GT (2011) Designing and manufacturing an auricular prosthesis using computed tomography, 3-dimensional photographic imaging, and additive manufacturing: A clinical report. J Prosthet Dent 105(2): 78-82.

6. Feng Z, Dong Y, Zhao Y, Bai S, Zhou B, et al. (2010) Computer-assisted technique for the design and manufacture of realistic facial prostheses. Br J Oral Maxillofac Surg 48(2): 105-109.

7. Melchels F, Wiggenhauser PS, Warne D, Barry M, Ong FR, et al. (2011) $\mathrm{CAD} / \mathrm{CAM}$-assisted breast reconstruction. Biofabrication 3(3).

8. World's first life-saving 3D printed kidney changing the game for surgical operations (2019).

9. DUrso PS, Earwaker WJ, Barker TM, Redmond MJ, Thompson RG, et al. (2000) Custom cranioplasty using stereolithography and acrylic. Br J Plast Surg 53(3): 200-204.

10. Singare S, Liu Y, Li D, Lu B, Wang J, et al. (2008) Individually prefabricated prosthesis for maxilla reconstruction. J Prosthodont 17(2): 135-140.

11. Mahmood F, Owais K, Taylor C, Montealegre Gallegos M, Manning W, et al. (2015) Three-dimensional printing of mitral valve using echocardiographic data. JACC Cardiovasc Imaging 8(2): 227-229.

12. Dai KR, Yan MN, Zhu ZA, Sun YH (2007) Computer-aided custom-made hemipelvic prosthesis used in extensive pelvic lesions. J Arthroplasty 22(7): 981-986.

13. Harrysson OLA, Hosni YA, Nayfeh JF (2007) Custom-designed orthopedic implants evaluated using finite element analysis of patient-specific computed tomography data: femoral-component case study. BMC Musculoskelet Disord 8(1): 91.

14. Rengier F, Mehndiratta A, Von Tengg Kobligk H, Zechmann CM, Unterhinninghofen R, et al. (2010) 3D printing based on imaging data: Review of medical applications. Int J Comput Assist Radiol Surg 5(4): 335-341.

15. Armillotta, Bonhoeffer P, Dubini G, Ferragina S, Migliavacca F, et al. (2007) Use of rapid prototyping models in the planning of percutaneous pulmonary valved stent implantation," Proc. Inst. Mech. Eng Part H J Eng Med 221(4): 407-416. 
16. Sulaiman, Loîc Boussel, Frédéric Taconnet, Jean Michel Serfaty, Hasan Alsaid et al. (2008) In vitro non-rigid life-size model of aortic arch aneurysm for endovascular prosthesis assessment. Eur J Cardio-Thoracic Surg 33(1): 53-57.

17. Paul GM, Rezaienia A, Wen P, Condoor S, Parkar N, et al. (2018) Medical Applications for 3D Printing: Recent Developments. Mo Med 115(1): 7581
18. Mitsouras D, Liacouras $\mathrm{P}$, Imanzadeh A, Giannopoulos AA, Cai T, et al. (2015) Medical 3D printing for the radiologist. Radiographics 35(7): 1965-1988. 